\title{
AIR STREAM VELOCITY MODELLING IN MULTICHANNEL SPIRAL CYCLONE SEPARATOR
}

\author{
Petras Vaitiekūnas, Egidijus Petraitis, Albertas Venslovas, Aleksandras Chlebnikovas \\ Institute of Environmental Protection, Vilnius Gediminas Technical University, Sauletekio al. 11, \\ 10223 Vilnius, Lithuania
}

Submitted 06 Nov. 2013; accepted 30 May 2014

\begin{abstract}
Numerical modelling problem is investigated in a gas aerodynamics multichannel spiral cyclone separator with a tangential inflow. Experimental and theoretical papers analysing cyclone separator with particularly complex turbulent flow were reviewed. The three-dimensional transport differential equations for incompressible laminar and turbulent flow inside the cyclone separator were presented. They were numerically solved by finite volume method using the Re-Normalisation Group (hereinafter RNG) $k$ - $\varepsilon$ turbulence model. The numerical air flow movement was modelled in cyclone separator with the following dimensions: $0.95 \mathrm{~m}$ height, $0.330 \mathrm{~m}$ diameter, $0.88 \mathrm{~m}$ height of spiral-cylindrical part, $0.39 \mathrm{~m}$ height of conical part, inflow dimensions (on the side of cylindrical part) according to the drawings were $\mathrm{a} \times \mathrm{b}=28 \times 95 \mathrm{~mm}$. The mathematical model of air flow movement in cyclone separator was composed by Navier-Stokes (Reynolds) as the three-dimensional differential equation system. The modelling results were obtained by the tangential and axial velocity profiles in cyclone separator using RNG k- $\varepsilon$ turbulence model, the inflow velocity from $4.1 \mathrm{~m} / \mathrm{s}$ to $15.4 \mathrm{~m} / \mathrm{s}$ coincided well with the experimental results. This is the first article testing for multichannel cyclone and determined distributions of aerodynamic parameters. The absolute error between experimental and modelling results changed from 0.01 to 0.24 units.
\end{abstract}

Keywords: spiral, cyclone separator, solid particles, numerical modelling, turbulence, single-phase flow general terms, air cleaning technologies.

\section{Introduction}

Cyclone separator is used for various purposes, but most often it is used for the separation of the dense phase in a multiphase flow. The entrance of flow into cyclone can be axial or tangential through the inlet section, which can be in different shapes for each cyclone (Avci, Karagoz 2003). Tangential entry cyclones are widely used for the separation of solid particles from the gas stream (Altmeyer $e t$ al. 2004; Kaya, Karagoz 2008).

Cyclone separators are some of the most widely used devices for gas cleaning and removing the solid particles from them. This device is classified as dry air treatment equipment according to the treatment method, and can be used in various industries where solid particle emission occurs. Solid particles are formed in combustion, chemical reactions, drying, transportation of dry materials, mining, metallurgy and moulding industries, coal boilers and electric power plants, building materials industry (cement, lime, ceramics, etc.), processing industry, food (dry milk, infant formulas, yeast, etc.) production (Vaitiekūnas, Jakštoniené 2010).

Fluid mixture enters the cyclone and makes a swirl motion, and, due to the centrifugal forces, the dense phase of the mixture gains a relative motion in the radial direction and is separated from the main flow. It is difficult to analyse this problem, since, in addition to its $3 \mathrm{D}$ character, many other parameters influence this flow (Avci, Karagoz 2003; Vasile et al. 2012).

Cyclones are incomparable leaders among other air cleaning equipment used to remove particulate matter from contaminated air flows. Cyclones are relatively expensive to construct, have a rather simple design, and are easy to maintain. Cyclone separators will remain competitive in the market of air cleaning devices for a long time due to relatively simple construction, absence of moving parts and filtering surfaces that require regular service, comparatively low wind resistance, and high efficiency (Patterson, Munz 1996; Sandu et al. 2012; Gujun et al. 2008).

Corresponding author: Aleksandras Chlebnikovas

E-mail: aleksandras.chlebnikovas@vgtu.lt 
The main weakness in the performance of standard reverse flow cyclone separators is insufficient removal of particulate matter from the gas flow, especially particles smaller than $10 \mu \mathrm{m}$ in diameter. Therefore, cyclones are most often used as pre-cleaners to remove dry, non-sticky particles. Air cleaning efficiency also decreases with the increase of air flow rate above $15 \mathrm{~m} / \mathrm{s}$ because of the resulting suction in the inlet and conical hull joints of cyclone separators. Cyclones are usually characterized by high flow resistance, which increases the energy costs during operation and limits the device performance (Gimbun et al. 2005).

Next-generation multichannel cyclones analysed in this paper are designed by installing the tangential air flow inlet according to aerodynamic characteristics of cyclones to achieve higher productivity and efficiency compared to conventional devices. These devices, with considerably improved design compared to conventional cyclones, are used to separate dry particles from the gas-air flow. Multichannel cyclone separators are gas cleaning devices with curvilinear channels; they are easily installed and operated. Operation of multichannel cyclone separator is based on centrifugal forces and the resulting additional filtration process in the separation chamber. Inside the device, there are cylindrical half-rings of a different radius arranged opposite to each other. The half-rings create a curved channel with a closed-loop system. Additional filtration occurs as the result of traffic interactions of the gas-air coming from the subsequent channel (peripheral) and running towards the channel axis of the device (transit). The air flow is filtered in the peripheral channel, i.e. a curtain formed after the curved half-ring separation zone increases the cleaning efficiency (Zhao et al. 2006).

Cyclone separator efficiency is hard to calculate due to the influence of the flow type. In large separators, the flow type is usually turbulent and the friction factors as well as calculated losses are important. In small cyclones, however, the flow and operating conditions, such as speed, pressure, viscosity, or the diameter of the cyclone, are more important. The flow in these cyclones can be laminar, turbulent, or transitional (Saltzman, Hochstrasser 1983). When the flow from the transit or peripheral channel of the cyclone enters the previous/following channel, the deceleration of the flow rate occurs in the separation zone. With the decrease of the Reynolds number the turbulence diminishes and the flow becomes laminar. The operating parameters have a greater impact on the efficiency of the cyclone separator in the case of laminar flow than in the case of turbulent flow. It is much more difficult to predict the effect of flow regime on the efficiency and pressure losses in small cyclones than the effect of geometrical parameters (Avci, Karagoz 2003; Gong, Wang 2004).

Computational Fluid Dynamics (CFD) is a potential tool for the forecasting of flow characteristics, particle trajectories, gaseous pollutants (Vaitiekūnas, Banaitytè 2007), and the pressure drop inside the cyclone separator (Gimbun et al. 2005, Baltrènas et al. 2008a; Baltrènas, Zagorskis 2010).

Insufficient understanding of the essence of the twophase flow process in a cyclone separator is caused by the fact that despite of its supposed simplicity, the flow dynamics in cyclones is complex. It includes such features as a whirling movement, and in some cases, several backflow circular areas. Closed vortex flow theories have so far failed to distinguish many peculiarities of the flow fields. The problem related to the detailed flow structure mathematical modelling involves closely related mass and momentum conservation nonlinear partial differential equation solution and has no solution. In addition, the assessment of turbulence based on the isotropy assumption (e.g. turbulent viscosity hypothesis) cannot be analytically applied in the case of rapidly swirling flows (Bernardo et al. 2006). A similar opinion is expressed in the papers of other scholars (Hoffmann, Stein, 2002; Hu et al. 2005; Raoufi et al. 2008).

Meier and Mori presented time-averaged Navier-Stokes equations for the gas phase related with the anisotropic turbulence model in the combination with $\mathrm{k}-\varepsilon$ model and algebraic stress equations (Meier, Mori 1999). Several studies were conducted where turbulence was modelled to improve the speed predictability and pressure. All these studies were based on axial symmetry and a two-dimensional model, where the solid phase almost does not meet the gas field due to low inlet concentration (Baltrènas et al. 2008b, 2012).

Recently, multichannel cyclone-filters have been introduced to collect dust generated in industrial processes (Jakštonienè et al. 2011; Jakštonienè 2012; Luca et al. 2012).

This is the first article describing the testing of a multichannel cyclone and determined distribution of aerodynamic parameters. Such research is necessary for the future development of the cyclone separators. The aim of this research is to test the cleaning efficiency of a multi-stage cyclone separator.

The objective of the test described in this paper is to conduct a numerical modelling of the air flow in a multichannel spiral cyclone separator using three-dimensional transport equations with Re-Normalisation Group (RNG) turbulence kinetic energy-turbulent kinetic energy dissipation rate turbulence model $(\mathrm{k}-\varepsilon)$ turbulence model and to compare the obtained results with the results of experimental studies.

\section{Research methodologies}

The drawing of the tested spiral multichannel cyclone separator is presented in Figure 1. 
The experimental multichannel spiral cyclone separator is located in the Environmental Protection Technology Laboratory of Vilnius Gediminas Technical University (VGTU).

The dynamic pressure of single-phase gas (air) flow was measured using Pitot-Prandtl tube connected to a dynamic set-top box. Multi-function meter Testo 400 was used for data receiving and dynamic pressure conversion into flow rate.

Measurements were made on the following characteristic points of separation chamber inside the device: at the beginning, middle, and the end of the channel, and also at the intermediate points (between the beginning and the middle of the channel, and between the middle and the end). Pitot-Prandtl tube was inserted through special holes made in the separation chamber cover plate at the characteristic points. The speed setting for the reliability of results was performed along the entire cross-section of each cyclone separator channel, by making a 9-point network (on the periphery boundary layer, in the middle of each channel cross-section, and on the inner wall of the channel). The dynamic pressure and resistance were measured three times in order to minimize the test error. All velocities were measured by changing the airflow yield supplied by the channel ventilator. The supplied airflow was changed with a lever of ventilator's control unit.

The following equipment was used for the research:

- Multi-function meter Testo 400 (temperature range $20-70{ }^{\circ} \mathrm{C}$, error $\pm 0.2^{\circ} \mathrm{C}$, speed measuring range $1-30 \mathrm{~m} / \mathrm{s}$, error $\pm 0.05 \mathrm{~m} / \mathrm{s}$ );

- Pitot-tube (Prandtl), error $\pm 2.2 \%$;

- Dynamic set-top box.

The experimental tests were conducted by placing the curved half-rings in such a manner that the air flow leaving channels $2-5$ would be distributed into the transit (entering the next channel) and peripheral (returning to the previous channel) flows at the ratio $50 / 50 \%$ (Fig. 6). In this way, the volume of the returning (and moving to the next channel toward the cyclone separator axis) air flow was half lower than the volume of the flow moving along the channel before the flow separation. Air flow rates of $4.1 \mathrm{~m} / \mathrm{s}, 12.2 \mathrm{~m} / \mathrm{s}$ and $15.4 \mathrm{~m} / \mathrm{s}$ were selected in order to achieve adequate air flow amount $\left(60 \mathrm{~m}^{3} / \mathrm{h}, 180 \mathrm{~m}^{3} / \mathrm{h}\right.$, and $230 \mathrm{~m}^{3} / \mathrm{h}$ ). Three inlet velocities were selected to compare changes in air velocity distribution. These air flow amounts are suitable for low-rate treatment systems.

Turbulent flows seem to be rather complex. This complexity is reflected in turbulent flow equations, such as Equation (1) and Equation (2), where a supplementary member, a Reynolds number appears. While modelling these members, we tried to provide simple relationships in the final form of equations that are solved by the numerical methods; it is a simplification of comprehensive equations. This means that the simplification can be so

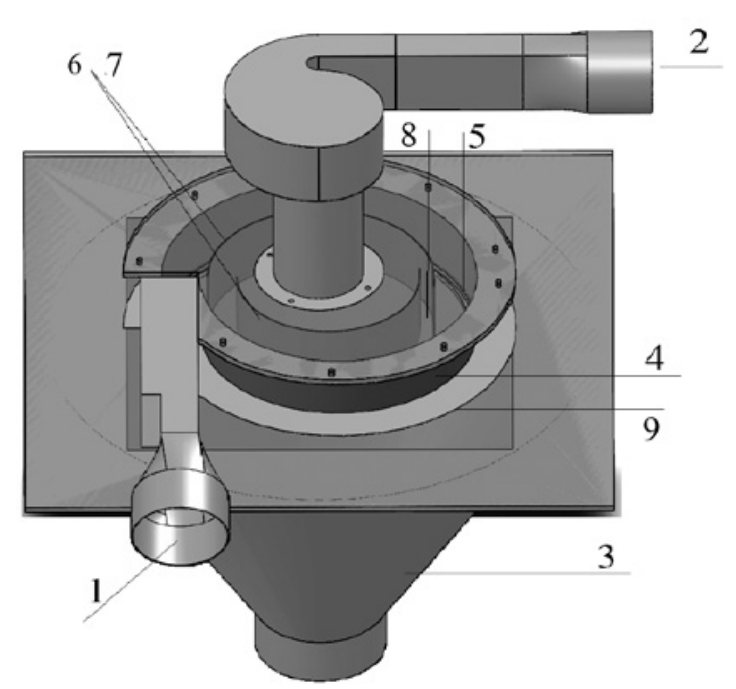

Fig. 1. Experimental spiral multichannel cyclone separator: contaminated solid particles in the air flow inlet (1); purified air outlet (2); conical hopper (3); spiral-shaped separation chamber (4) with sectional ring slits (5); curved channels (6) with cylindrical half-rings of different radius (7), spacing between the curved channels (8); spiral casing of the cyclone separator well (9)

broad that it reduces the accuracy of mathematical model describing the flow. Differential transport equations using the turbulent viscosity hypothesis are (Vaitiekūnas, Jakštonienè 2010):

$$
\begin{aligned}
& \rho\left(\frac{\partial u}{\partial t}+u \frac{\partial u}{\partial x}+v \frac{\partial u}{\partial y}+w \frac{\partial u}{\partial z}\right)= \\
& \rho F_{x}-\frac{\partial p}{\partial x}+\mu\left(\frac{\partial^{2} u}{\partial x^{2}}+\frac{\partial^{2} u}{\partial y^{2}}+\frac{\partial^{2} u}{\partial z^{2}}\right)-\rho\left(\frac{\partial{\overline{u^{\prime}}}^{2}}{\partial x}+\frac{\partial \overline{u^{\prime} v^{\prime}}}{\partial y}+\frac{\partial \overline{u^{\prime} w^{\prime}}}{\partial z}\right) \\
& \rho\left(\frac{\partial v}{\partial t}+u \frac{\partial v}{\partial x}+v \frac{\partial v}{\partial y}+w \frac{\partial v}{\partial z}\right)= \\
& \rho F_{y}-\frac{\partial p}{\partial y}+\mu\left(\frac{\partial^{2} v}{\partial x^{2}}+\frac{\partial^{2} v}{\partial y^{2}}+\frac{\partial^{2} v}{\partial z^{2}}\right)-\rho\left(\frac{\partial \overline{u^{\prime} v^{\prime}}}{\partial x}+\frac{\partial \bar{v}^{\prime 2}}{\partial y}+\frac{\partial \overline{v^{\prime} w^{\prime}}}{\partial z}\right) \\
& \rho\left(\frac{\partial w}{\partial t}+u \frac{\partial w}{\partial x}+v \frac{\partial w}{\partial y}+w \frac{\partial w}{\partial z}\right)= \\
& \rho F_{z}-\frac{\partial p}{\partial z}+\mu\left(\frac{\partial^{2} w}{\partial x^{2}}+\frac{\partial^{2} w}{\partial y^{2}}+\frac{\partial^{2} w}{\partial z^{2}}\right)-\rho\left(\frac{\partial \overline{u^{\prime} w^{\prime}}}{\partial x}+\frac{\partial \overline{y^{\prime} w^{\prime}}}{\partial y}+\frac{\partial \overline{w^{\prime}}}{\partial z}\right) \\
& \frac{\partial u}{\partial x}+\frac{\partial v}{\partial y}+\frac{\partial w}{\partial z}=0
\end{aligned}
$$

where: $p$ - pressure, N/m, Pa; $\mu$ - molecular viscosity coefficient, $\mathrm{N} \times \mathrm{s} / \mathrm{m}^{2} ; \rho$ - density, $\mathrm{kg} / \mathrm{m}^{3} ; F_{x}, F_{y}, F_{z}$ - the mass force vector projections onto the coordinate axes; $u, v$, $w$ - component of velocity by an axis; $x, y, z$ - coordinate axis; $\frac{\partial u}{\partial t}, \frac{\partial v}{\partial t}, \frac{\partial w}{\partial t}$ - variables $u, v, w$ derived by time $t$; $\frac{\partial \bar{u}^{\prime}}{\partial x}, \frac{\partial{\overline{u^{\prime} v^{\prime}}}^{\prime}}{\partial x}, \frac{\partial{\overline{v^{\prime}}}^{2}}{\partial y}, \frac{\partial \overline{v^{\prime} w^{\prime}}}{\partial z}$ - pulse rate change by the axis $\mathrm{x}$, 
y, z. Reynolds stress and pulse values were not calculated. The calculation was based on eddy-viscosity hypothesis.

All three (1) types of equations will give nine turbulent stresses, called the Reynolds stresses, forming stress tensor, and if there is the symmetry condition, it is:

$$
\left|\begin{array}{ccc}
\sigma_{x x} & \tau_{x y} & \tau_{x z} \\
\tau_{y x} & \sigma_{y y} & \tau_{y z} \\
\tau_{z x} & \tau_{z y} & \sigma_{z z}
\end{array}\right| \equiv-\rho\left|\begin{array}{lll}
\overline{u^{\prime}} & \overline{u^{\prime} v^{\prime}} & \overline{u^{\prime} w^{\prime}} \\
\overline{u^{\prime} v^{\prime}} & \overline{v^{\prime}} & \overline{v^{\prime} w^{\prime}} \\
\overline{u^{\prime} v^{\prime}} & \overline{v^{\prime} w^{\prime}} & \overline{w^{\prime}}
\end{array}\right|,
$$

where: $\sigma$ - normal stresses; $\tau$ - tangential stresses.

Reynolds stresses are considered to have the form, similar to viscous moment equation stresses. Eddy-viscosity with three (1) equations can be expressed by the following equation:

$\rho\left(\frac{\partial u}{\partial t}+u \frac{\partial u}{\partial x}+v \frac{\partial u}{\partial y}+w \frac{\partial u}{\partial z}\right)=$

$\rho F_{x}-\frac{\partial p}{\partial x}+\frac{\partial}{\partial x}\left[\left(\mu+\mu_{T}\right) \frac{\partial u}{\partial x}\right]+\frac{\partial}{\partial y}\left[\left(\mu+\mu_{T}\right) \frac{\partial u}{\partial y}\right]+\frac{\partial}{\partial z}\left[\left(\mu+\mu_{T}\right) \frac{\partial u}{\partial z}\right]$,

$\rho\left(\frac{\partial v}{\partial t}+u \frac{\partial v}{\partial x}+v \frac{\partial v}{\partial y}+w \frac{\partial v}{\partial z}\right)=$

$\rho F_{y}-\frac{\partial p}{\partial y}+\frac{\partial}{\partial x}\left[\left(\mu+\mu_{T}\right) \frac{\partial v}{\partial x}\right]+\frac{\partial}{\partial y}\left[\left(\mu+\mu_{T}\right) \frac{\partial v}{\partial y}\right]+\frac{\partial}{\partial z}\left[\left(\mu+\mu_{T}\right) \frac{\partial v}{\partial z}\right]$,

$\rho\left(\frac{\partial w}{\partial t}+u \frac{\partial w}{\partial x}+v \frac{\partial w}{\partial y}+w \frac{\partial w}{\partial z}\right)=$

$\rho F_{z}-\frac{\partial p}{\partial z}+\frac{\partial}{\partial x}\left[\left(\mu+\mu_{T}\right) \frac{\partial w}{\partial x}\right]+\frac{\partial}{\partial y}\left[\left(\mu+\mu_{T}\right) \frac{\partial w}{\partial y}\right]+\frac{\partial}{\partial z}\left[\left(\mu+\mu_{T}\right) \frac{\partial w}{\partial z}\right]$.

Equation (4) is obtained from Equation (1) by applying the Reynolds method. The RNG model was developed using RNG methods by Yakhot et al. (1992) to re-normalise the Navier-Stokes equations, to account for the effects of smaller scales of motion. In the standard

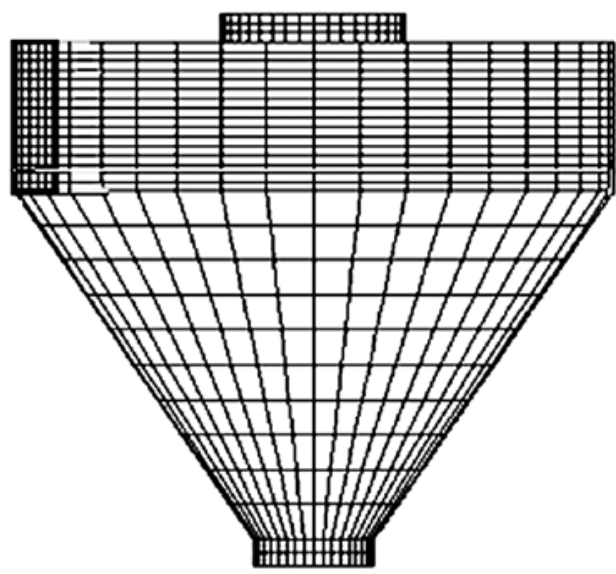

Fig. 2. Multi-channel cyclone computing grid sketch: inlet (at the top of cylinder, inlet area $\mathrm{a} \times \mathrm{b}=28 \times 95 \mathrm{~mm}$ ); two outlets - at the bottom, for solid particles and a pipe with diameter $\mathrm{R}=0.0245 \mathrm{~m}$ $\mathrm{k}$-epsilon model, the eddy viscosity is determined from a single turbulence length scale, so the calculated turbulent diffusion is that which occurs only at the specified scale, whereas in reality all scales of motion will contribute to the turbulent diffusion. The RNG approach - a mathematical technique that can be used to derive a turbulence model similar to the k-epsilon - results in a modified form of the epsilon equation which accounts for the different scales of motion through changes to the production term. This model also includes analytical expressions to obtain $R$ member in equation. Transport equations for variables $k$ and $\varepsilon$ in RNG $k-\varepsilon$ model that is obtained from the NavierStokes equations using the theory of groups of normalization is (Shaw 1992):

$$
\begin{gathered}
\mu_{T}=\rho C_{\mu} \frac{k^{2}}{\varepsilon} ; \\
\rho \frac{D k}{D t}=\frac{\partial}{\partial x_{i}}\left(a_{k} \mu_{e f f} \frac{\partial k}{\partial x_{i}}\right)+G_{k}-\rho \varepsilon ; \\
\rho \frac{D \varepsilon}{D t}=\frac{\partial}{\partial x_{i}}\left(a_{\varepsilon} \mu_{e f f} \frac{\partial \varepsilon}{\partial x_{i}}\right)+C_{1 \varepsilon} \frac{\varepsilon}{k} G_{k}-C_{2 \varepsilon} \rho \frac{\varepsilon^{2}}{k}-R,
\end{gathered}
$$

where: $\mu_{T}$ - turbulent viscosity coefficient; $\mu_{\text {eff }}=\mu+\mu_{T}$; $G_{k}$ - constants; $k$ - turbulence kinetic energy, $k=(1 / 3)$ $\left(u^{\prime} 2+v^{\prime} 2+w^{\prime} 2\right) 1 / 2 ; i=1,2,3 ; \varepsilon-$ turbulent kinetic energy dissipation rate; $\mathrm{C}_{\mu}-0.0845 ; \mathrm{C}_{1 \varepsilon}-1.42 ; \mathrm{C}_{2 \varepsilon}-1.68$ (Yakhot et al. 1992). Equations (4) and (5) must be supplemented by the second row RNG $k$-epsilon turbulence model Equations (6) and (7); mathematical model consists of five differential equations for variables $u, v, w, k, \varepsilon$.

\section{The initial and boundary conditions}

The numerical model of cyclone separator is composed according to the physical model (Fig. 1), its discretization dividing the cylindrical space by finite volume elements (Fig. 2), where all five variables have initial values in each element. Boundary conditions of (4) and (5) equations are: inflow (for all 5 variables), outflow (zero pressure value), the speed of sticking to solid walls (cyclone interior, half-rings of both sides: $u=v=w=0$ ).

Figure 2 illustrates the cyclone separator modelling sphere presented in three-dimensional cylindrical coordinate system that is divided into cells in $x y, z$ coordinates axes (Fig. 2) (Bernardo et al. 2005). Cyclone network area in general case consists of $x \times y \times z=60 \times 36 \times 24=$ 51,840 volumetric cells. These are control volume cells, where radial, tangential and axial direction velocity components, pressure, bulk-phase parts, turbulence characteristics are calculated.

The described equations are solved numerically by finite volume method (Spalding 2002). The computational domain is discretized into a number of cells according to the concept of finite volume. The differential equations 
are integrated on each cell using the divergence theorem (Gauss-Ostrogradski theorem) obtaining discrete, i.e. algebraic equations that are solved iteratively, thus obtaining fields of dependent variables.

Figure 3 illustrates the velocity vector field of the vertical cyclone separator plane, when the inflow velocity is $5.1 \mathrm{~m} / \mathrm{s}$.

Figure 3 shows an asymmetrical vector field distribution because of tangential inlet in the upper part of the cyclone.

\section{Results and analysis}

The comparisons between the numerical and experimental tangential velocity profiles of the gas were performed when the axial position $\mathrm{z}=0.05 \mathrm{~m}$ from the top of the cyclone separator. These results were obtained using the RNG turbulence model and were similar to the experimental data (Fig. 4, Fig. 5, Table 1, Table 2).

The maximum speed was recorded when $z=0.05 \mathrm{~m}$, $x=0$ and $U_{1}=4.1 \mathrm{~m} / \mathrm{s}$. The velocity in channel $\mathrm{IV}$ of cyclone separator decreases to $4 \mathrm{~m} / \mathrm{s}$ and the velocity near the axis is only $1 \mathrm{~m} / \mathrm{s}$. This is because the cleaned air goes up along $\mathrm{z}$ axis.

The diagram of presented modelling and experimental air flow velocities in channel I (Fig. 5) shows that the experimental air flow velocity curve intersects and is intertwined with the modelling velocity curve.

The diagram shows that air flow velocities obtained at point 1 of the modelling case differ by 1.1 units from the experimental velocities.

The comparative velocities in points 2,3 , and 4 are similar. The velocity obtained in point 5 in the experiment is 2.1 units higher than in the modelling case.

It can be concluded that air flow velocity obtained during numerical modelling in channel I corresponds to the experimental velocity as the values in three points coincide and the values in two remaining points differ insignificantly.

The highest absolute error was determined in point 5 in the first channel of the cyclone. The absolute error between experimental and modelling results is equal to 0.4 or $40 \%$.

Table 1 and Table 2 illustrate experimental and numerical modelling air flow velocity results in six channels; five measuring points; averages and absolute errors are calculated too.

The data in Table 1 and Table 2 (tangential velocity profile results obtained by experimental research and numerical modelling methods) are graphically shown in Figure 7, where the gas flow velocity curves in six multichannel spiral cyclone separator channels are given.

Table 1, Table 2 and Figure 5 show that the average duct air velocity in channel I is about $4.1 \mathrm{~m} / \mathrm{s}, 12.2 \mathrm{~m} / \mathrm{s}$

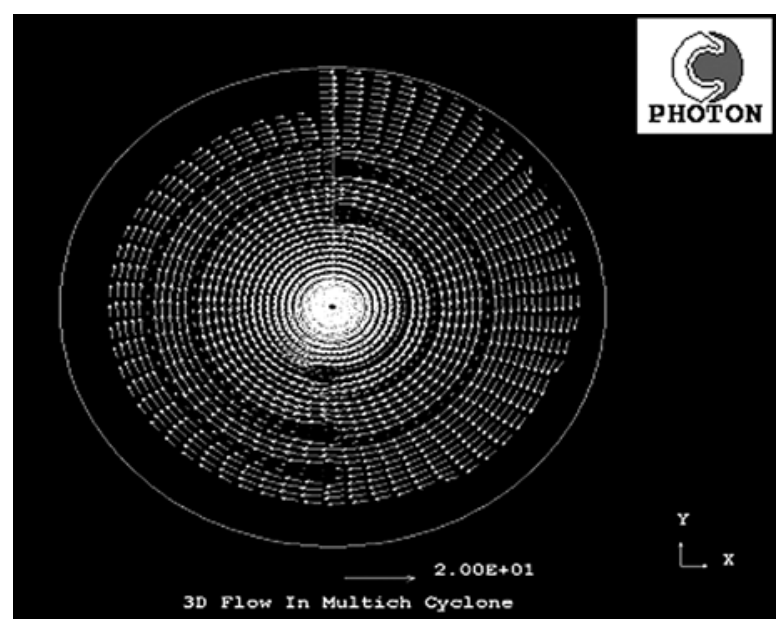

Fig. 3. Mid-plane z velocity vectors: inlet velocity $5.1 \mathrm{~m} / \mathrm{s}$.; the scale of velocity vectors $-20.0 \mathrm{~m} / \mathrm{s}$, from the top of the separation chamber of cyclone is $z=0.05 \mathrm{~m}$
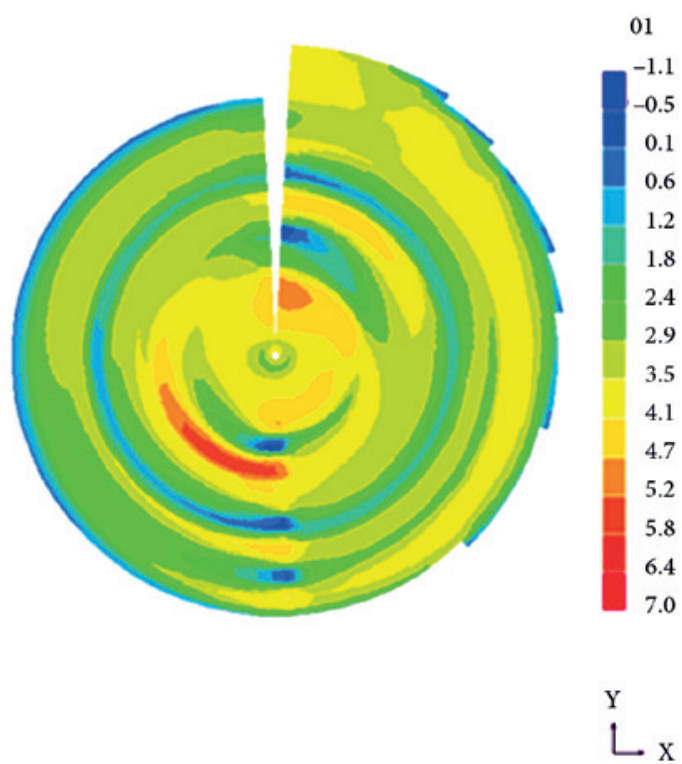

Fig. 4. Single-phase flow rate in multi-channel cyclone, where the distance $\mathrm{z}$ from the top of the separation chamber of cyclone is $\mathrm{z}=0.05 \mathrm{~m}$

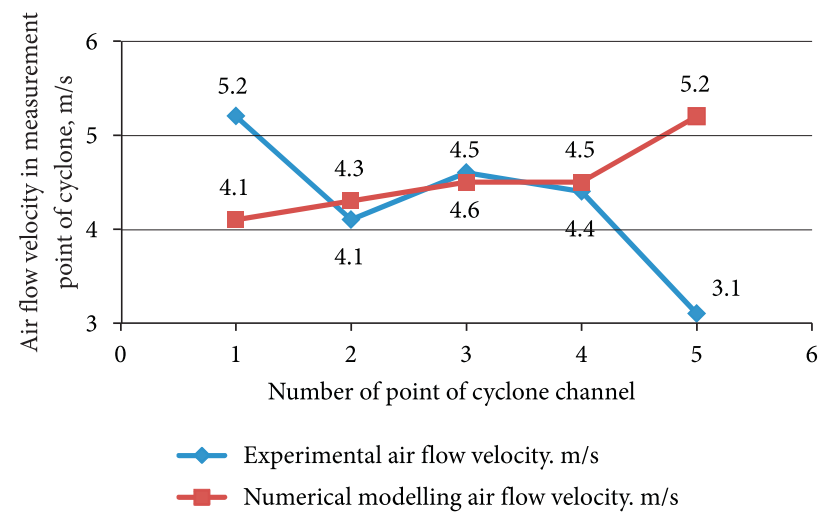

Fig. 5. Experimental studies and numerical simulations to obtain the gas flow shear velocities in the first channel of cyclone 
Table 1. Change of the velocity (experimental and modelling) in cyclone separator channels of spiral corps depending on the position and geometry of curvilinear semi-rings $\left(U_{\text {in }}=4.1 \mathrm{~m} / \mathrm{s}\right.$ and $\left.U_{\text {in }}=12.2 \mathrm{~m} / \mathrm{s}\right)$

\begin{tabular}{|c|c|c|c|c|c|c|c|c|}
\hline \multicolumn{8}{|c|}{6 channel spiral cyclone separator, $4.1 \mathrm{~m} / \mathrm{s}$ inlet velocity $\left(\mathrm{U}_{\text {in }}\right)$} & \multirow{2}{*}{ Absolute averaged error, unit ${ }^{1}$} \\
\hline & & 1 & 2 & 3 & 4 & 5 & Average & \\
\hline \multirow{13}{*}{$\begin{array}{l}\text { Cyclone } \\
\text { separator } \\
\text { channel }\end{array}$} & 1 channel. exp. r. & 4.1 & 4.3 & 4.5 & 4.5 & 5.2 & 4.5 & \multirow{2}{*}{0.04} \\
\hline & 1 channel. num. $r$. & 5.2 & 4.1 & 4.6 & 4.4 & 3.1 & 4.3 & \\
\hline & 2 channel. exp. r. & 5.0 & 4.8 & 4.8 & 4.4 & 4.4 & 4.7 & \multirow{2}{*}{0.02} \\
\hline & 2 channel. num. $r$. & 5.1 & 4.6 & 4.7 & 4.6 & 4.2 & 4.6 & \\
\hline & 3 channel. exp. r. & 4.4 & 4.4 & 4.3 & 3.9 & 3.9 & 4.2 & \multirow{2}{*}{0.07} \\
\hline & 3 channel. num. $r$. & 4.3 & 4.7 & 4.9 & 4.3 & 4.1 & 4.5 & \\
\hline & 4 channel. exp. r. & 4.2 & 4.4 & 4.6 & 4.7 & 4.7 & 4.5 & \multirow{2}{*}{0.02} \\
\hline & 4 channel. num. $r$. & 4.5 & 4.6 & 4.8 & 4.8 & 4.5 & 4.6 & \\
\hline & 5 channel. exp. r. & 4.7 & 4.8 & 4.8 & 5.0 & 5.1 & 4.9 & \multirow{2}{*}{0.04} \\
\hline & 5 channel. num. $r$. & 4.1 & 4.6 & 4.9 & 5.1 & 4.9 & 4.7 & \\
\hline & 6 channel. exp.r. & 5.1 & 5.1 & 5.2 & 5.2 & 5.3 & 5.2 & \multirow{2}{*}{0.08} \\
\hline & 6 channel. num. r. & 4.7 & 4.5 & 4.7 & 4.9 & 5.0 & 4.8 & \\
\hline & & & & & & & Average: & 0.05 \\
\hline \multicolumn{8}{|c|}{6 channel spiral cyclone separator, $12.2 \mathrm{~m} / \mathrm{s}$ inlet velocity $\left(\mathrm{U}_{\text {in }}\right)$} & \multirow[t]{2}{*}{ Absolute averaged error, unit $^{1}$} \\
\hline \multirow{14}{*}{$\begin{array}{l}\text { Cyclone } \\
\text { separator } \\
\text { channel }\end{array}$} & & 1 & 2 & 3 & 4 & 5 & Average & \\
\hline & 1 channel. exp. r. & 12.2 & 12.2 & 12.2 & 12.8 & 11.5 & 12.2 & \multirow{2}{*}{0.02} \\
\hline & 1 channel. num. $\mathrm{r}$. & 12.5 & 11.8 & 12.2 & 11.8 & 11.1 & 12.4 & \\
\hline & 2 channel. exp. r. & 12.0 & 11.9 & 12.6 & 12.6 & 12.1 & 12.2 & \multirow{2}{*}{0.08} \\
\hline & 2 channel. num. $r$. & 12.0 & 10.7 & 11.4 & 10.7 & 11.1 & 11.2 & \\
\hline & 3 channel. exp. r. & 11.6 & 12.4 & 13.2 & 12.7 & 12.9 & 12.6 & \multirow{2}{*}{0.06} \\
\hline & 3 channel. num. $\mathrm{r}$. & 14.1 & 11.8 & 11.4 & 14.5 & 12.5 & 11.8 & \\
\hline & 4 channel. exp. r. & 12.2 & 11.9 & 11.6 & 11.9 & 12.2 & 12.0 & \multirow{2}{*}{0.03} \\
\hline & 4 channel. num. $\mathrm{r}$. & 12.0 & 11.2 & 11.5 & 11.5 & 11.6 & 11.6 & \\
\hline & 5 channel. exp.r. & 12.2 & 12.5 & 12.7 & 12.5 & 12.2 & 12.4 & \multirow{2}{*}{0.08} \\
\hline & 5 channel. num. $r$. & 10.3 & 12.2 & 11.5 & 11.5 & 11.2 & 11.4 & \\
\hline & 6 channel. exp. r. & 12.2 & 12.4 & 12.4 & 12.6 & 12.9 & 12.5 & \multirow{2}{*}{0.03} \\
\hline & 6 channel. num. $r$. & 12.8 & 12.6 & 12.4 & 10.7 & 12.1 & 12.1 & \\
\hline & & & & & & & Average: & 0.05 \\
\hline
\end{tabular}

${ }^{1}$ Absolute averaged error is determined by formula $\frac{\left|u_{a v . \exp .}-u_{a v . n u m .}\right|}{u_{a v . \exp .}}$, where: $u_{a v . \text { exp. }}$ - average velocity by experimental results; $u_{\text {av. num. }}$ - average velocity by numerical modelling results.

Table 2. Change of velocity (experimental and modelling) in cyclone separator channels of spiral corps depending on the position and geometry of curvilinear semi-rings $\left(U_{i n}=15.4 \mathrm{~m} / \mathrm{s}\right)$

\begin{tabular}{|c|c|c|c|c|c|c|c|c|}
\hline \multicolumn{8}{|c|}{6 channel spiral cyclone separator, $15.4 \mathrm{~m} / \mathrm{s}$ inlet velocity $\left(\mathrm{U}_{\text {in }}\right)$} & \multirow{2}{*}{ Absolute averaged error, unit ${ }^{1}$} \\
\hline & & 1 & 2 & 3 & 4 & 5 & Average & \\
\hline \multirow{13}{*}{$\begin{array}{l}\text { Cyclone } \\
\text { separator } \\
\text { channel }\end{array}$} & 1 channel. exp. $r$. & 15.4 & 15.5 & 12.7 & 16.2 & 16.6 & 15.9 & \multirow{2}{*}{0.06} \\
\hline & 1 channel. num. $r$. & 15.4 & 15.0 & 15.3 & 14.9 & 14.2 & 15.0 & \\
\hline & 2 channel. exp. r. & 16.4 & 16.9 & 15.6 & 16.4 & 16.9 & 16.4 & \multirow{2}{*}{0.09} \\
\hline & 2 channel. num. $r$. & 14.2 & 15.0 & 15.0 & 15.1 & 15.1 & 14.9 & \\
\hline & 3 channel. exp. r. & 16.2 & 16.5 & 16.9 & 15.8 & 16.2 & 16.3 & \multirow{2}{*}{0.01} \\
\hline & 3 channel. num. r. & 15.6 & 14.2 & 15.2 & 14.2 & 15.4 & 16.5 & \\
\hline & 4 channel. exp. r. & 16.5 & 16.5 & 16.5 & 16.7 & 16.5 & 15.2 & \multirow{2}{*}{0.24} \\
\hline & 4 channel. num. r. & 16.2 & 14.8 & 14.2 & 14.0 & 17.8 & 11.6 & \\
\hline & 5 channel. exp. r. & 16.5 & 16.5 & 16.6 & 16.8 & 17.0 & 16.7 & \multirow{2}{*}{0.05} \\
\hline & 5 channel. num. $r$. & 16.2 & 14.8 & 14.9 & 14.9 & 18.3 & 15.8 & \\
\hline & 6 channel. exp. r. & 17.0 & 16.8 & 16.7 & 15.7 & 16.9 & 16.8 & \multirow{2}{*}{0.04} \\
\hline & 6 channel. num. r. & 17.6 & 15.4 & 14.3 & 15.8 & 17.3 & 16.1 & \\
\hline & & & & & & & Average: & 0.08 \\
\hline
\end{tabular}

${ }^{1}$ Absolute averaged error is determined by formula $\frac{\left|u_{a v . \exp .}-u_{a v . n u m .}\right|}{u_{a v . \text { exp. }}}$, where: $u_{a v . \text { exp. }}-$ average velocity by experimental results; $u_{\text {av. num. }}$ - average velocity by numerical modelling results. 
and $15.4 \mathrm{~m} / \mathrm{s}$. Channel I differs from the experimental results respectively only by $0.04,0.02$ and 0.06 units. Figure 5 presents the air flow velocity in channel I during the modelling and experimental research.

Figure 7 shows that gas stream tangential velocity profile results obtained during the experiment can be identified with the numerical simulation results, as the error between those values is only $7.7 \%$.

The paper (Kaya, Karagoz 2008) concludes that these discrepancies arise not only due to turbulence model and numerical methods, but also because of experimental and measurement errors as the aerodynamic process in cyclone separator is highly influenced by the incoming flow and geometric conditions, and it is difficult to measure exactly the velocities in such a complex flow. Rapidly rotating fluid flow creates strong anisotropy in turbulence structure, and therefore the standard $k-\varepsilon$ and RNG $k-\varepsilon$ turbulent model provides inaccurate data on fluid flows. The comparison of two isotropic models shows that RNG $k-\varepsilon$ model provides slightly better results than the standard $k-\varepsilon$ model with the flow rotation and cross-flows.

The standard $k-\varepsilon$ model is more suitable for solid state rotation modelling than for obtaining the expected combined turbulences and also gives unrealistic axial velocity distribution (Kaya, Karagoz 2008).

The flow velocity values measured in the experimental set testing of six-channel cyclone separator (Fig. 6) range from $3.9 \mathrm{~m} / \mathrm{s}$ to $5.3 \mathrm{~m} / \mathrm{s}$. The total average measured velocity in all channels is $4.7 \mathrm{~m} / \mathrm{s}$. The velocity of the flow entering channel $\mathrm{I}$ is almost $12 \%$ lower than the average velocity in channels of the cyclone separator. However, the velocity is $5.2 \mathrm{~m} / \mathrm{s}$ when the flow is moving along the curved channel.

After the experimental research of aerodynamic characteristics the average velocities in cyclone separator channels were determined with the following inflow velocities: $4.1 \mathrm{~m} / \mathrm{s}$ - which correspond to $60 \mathrm{~m}^{3} / \mathrm{h}, 12.2 \mathrm{~m} / \mathrm{s}$ $180 \mathrm{~m}^{3} / \mathrm{h}$ and $15.4 \mathrm{~m} / \mathrm{s}-230 \mathrm{~m}^{3} / \mathrm{h}$ of cleaned air flow amount. The results are given in Table 1 and Table 2.

The gas (air) flow velocities were measured at the points shown in Figure 6. All data are grouped by channels, and measuring points in each channel. The obtained values show a significant change in the velocity inside the cyclone separator structure.

The analysis of flow velocity variation at the lowest cyclone separator efficiency showed that the lowest inflow rate was observed at the inlet of cyclone separator channel I. The resistance forces appear during the flow through the diffuser and the measured aerodynamic resistance of the system in this case is equal to $250 \mathrm{~Pa}$.

The velocity slightly increases when gas flow moves in the curved channel I of the cyclone (this is evident because of the spiral design) and through the narrower parts. 9.7\% higher than the inflow velocity was achieved in the

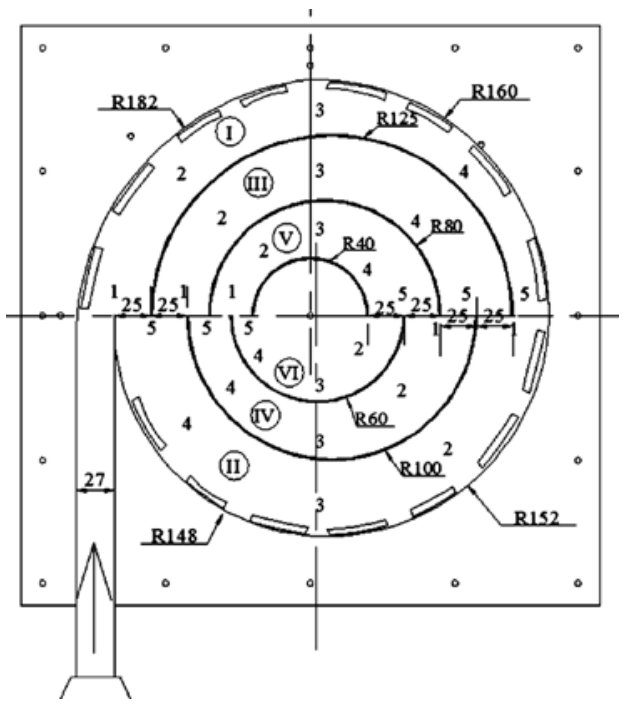

Fig. 6. The top view of the cylinder part of cyclone separator, 5 measurement points in each of the six channels

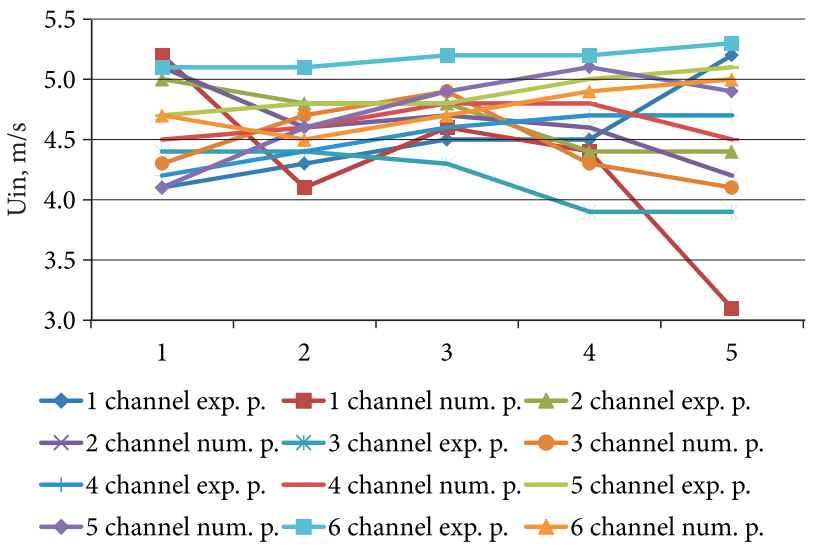

Fig. 7. Experimental studies and numerical simulations to obtain the gas flow tangential velocities in six channels of multi-channel spiral cyclone separator (5 points)

middle of channel I; it can be compared to the average velocity in channel I evaluating a slight difference.

The flow rate at the end of channel I is the highest and is equal to $5.2 \mathrm{~m} / \mathrm{s}$ in the place where the cross-sectional area is $0.0025 \mathrm{~m}^{2} .5 \mathrm{~m} / \mathrm{s}$ velocity is observed the beginning of channel II. The channel at this measurement point is limited by the peripheral wall with a radius of $154 \mathrm{~mm}$ and the second curved half-ring with a radius of $100 \mathrm{~mm}$.

The minimal velocities prevail at the end of the channel (points 4,5 ) and are equal to $4.4 \mathrm{~m} / \mathrm{s}$. There are two zones in channel III with very similar velocity values, i.e. in points 1,2 , and 3 the velocity value ranges from $4.3 \mathrm{~m} / \mathrm{s}$ to $4.4 \mathrm{~m} / \mathrm{s}$. Points 4 and 5 , where the measured velocity was $3.9 \mathrm{~m} / \mathrm{s}$, are in the second zone. The flow breaks and weakens and the speed increases in channels IV, V and VI.

The minimum velocity of $4.2 \mathrm{~m} / \mathrm{s}$ is set at the beginning of channel IV (at point 1), and near the middle of the channel (point 2) the velocity increases to $4.4 \mathrm{~m} / \mathrm{s}$. The 
velocities in the middle and towards the end of the channel (points 3, 4, and 5) vary range from 4.6 to $4.7 \mathrm{~m} / \mathrm{s}$. The sensitivity of velocity variation in channels IV-VI is influenced by small cross-sections of channels I, II and III. This proves that channel geometry variation has a much bigger effect on the change of aerodynamic parameters, such as velocity.

However, such changes are not observed in channels II and III. It can be argued that the flow becomes weaker after passing more than half of the channel length and cannot overcome the generated resistance, therefore the velocity reduces. This argument is supported by the fact that in both cases the velocity starts decreasing significantly only from the third measurement point with the exception of channels II and III. Compared to other changes in the channels, it should be noted that the cross-section of channel II is smaller than the cross-section of channel I, but the difference is less than 1.1 times compared to the changes of the spiral-shaped case s. Therefore the increase of the speed due to smaller cross-section is not significant.

Similar velocities ranging from 4.7 to $4.8 \mathrm{~m} / \mathrm{s}$ in channel $\mathrm{V}$ are distributed in points $1-3$; towards the end (point 4) they increase up to $5 \mathrm{~m} / \mathrm{s}$. The maximum velocity of channel $\mathrm{V}$ is set at the end of the channel (point 5) where $5.1 \mathrm{~m} / \mathrm{s}$ velocity is reached. The highest velocity values are set in channel VI; the velocity values are similar and range from 5.1 to $5.3 \mathrm{~m} / \mathrm{s}$. It should be noted that the maximum velocity in channel VI, which also has the maximum speed in the entire cyclone separator, reaches $5.3 \mathrm{~m} / \mathrm{s}$. The value is determined at the end of channel VI at point 5 . This value is almost 1.13 times higher than the average of all set average velocities in the channels.

The velocity is the lowest and is equal to $4.1 \mathrm{~m} / \mathrm{s}$ at the beginning of channel $I$ at point 1 ; in the middle and towards the end of the channel (points 3,4) the measured velocity values are $4.5 \mathrm{~m} / \mathrm{s}$. The flow stop at the beginning of the channel may be associated with higher resistance forces, which occur immediately after the entrance of the inflow duct to the cyclone separation chamber and cyclone channel I. However, the changes in the channel cross-sections that uniformly decrease because of the spiral-shape of multichannel cyclone separation chamber have the biggest influence on the increase of the flow velocity in the middle of channel I (point 3), the intermediate point (point 4) and at channel end (point 5). The width of Channel I, the distance between the periphery wall, and the first half rings evenly decreases and is less than 1.6 times than the initial width of channel I beyond the installation centre line (Fig. 3). Velocities in channel II are distributed in the opposite manner. The maximum velocity values of $5 \mathrm{~m} / \mathrm{s}$ are measured at the beginning of the channel (point 1), they become equal in the middle of the channel and reach $4.8 \mathrm{~m} / \mathrm{s}$.

The inflow velocities decreased by $4 \%$ because of slight increase of cross-sectional area; however, towards the middle and the end of the channel, the velocities increase and reach $4.4 \mathrm{~m} / \mathrm{s}$. The average velocity in channel II is $4.7 \mathrm{~m} / \mathrm{s}$, i.e., $4.5 \%$ higher than the velocity in channel I.

The velocity in channel III in all five measurement points remains fairly constant, but is still declining from $4.4 \mathrm{~m} / \mathrm{s}$ to $3.9 \mathrm{~m} / \mathrm{s}$. The velocity drop is influenced by the curved half-ring system, which acts as a barrier inhibiting the flow of gas, and increasing cross-sectional area from $0.004 \mathrm{~m}^{2}$ to $0.005 \mathrm{~m}^{2}$. The average velocity in channel III is $4.2 \mathrm{~m} / \mathrm{s}$.

The lowest velocity of all the cyclone separator channels is observed in channel III; this is because of one of the biggest cross-section and high resistance that affects the movement of the gas flow. The initial flow velocity in channel IV is $4.2 \mathrm{~m} / \mathrm{s}$ and it increases in a linear manner towards the end of the channel where it reaches $4.7 \mathrm{~m} / \mathrm{s}$. The velocity values increase in channels $\mathrm{V}$ and VI from the beginning of the channel towards the end, while the maximum velocity is reached at the end of channel VI, which is the highest in the whole cyclone separator and is equal to $5.3 \mathrm{~m} / \mathrm{s}$. Velocities in channels $\mathrm{V}$ and VI velocities are $4.9 \mathrm{~m} / \mathrm{s}$ and $5.2 \mathrm{~m} / \mathrm{s}$ respectively. The conclusion that the maximum velocities are measured in the inner channel VI can be done according to the channel velocity averages. The average velocities according to experimental research results also have a tendency to increase when approaching to the axis of the device, with the exception of channel III located in the middle of the device where the drop of velocity is observed.

An identical 6-channel cyclone separator with a spiral casing is analysed to investigate the assumption that it is three times more efficient than the separator discussed above. A gas flow of $180 \mathrm{~m}^{3} / \mathrm{h}$ is created to compare the experimental and modelling results. The inflow velocity into cyclone separator is $12.2 \mathrm{~m} / \mathrm{s}$ and remains steady in the entire channel I with the exception of measurement point 4 , where it rises to $12.8 \mathrm{~m} / \mathrm{s}$, and a sudden drop to $11.5 \mathrm{~m} / \mathrm{s}$ at the end of the channel. The spiral shape of cyclone separator causes higher extremes at higher velocities, especially at the end of the channel, although no extremes were observed with $5 \mathrm{~m} / \mathrm{s}$ velocities. The average velocity of the first channel is $12.2 \mathrm{~m} / \mathrm{s}$, i.e. 2.7 times higher than in the case of $60 \mathrm{~m}^{3} / \mathrm{h}$ air flow amount.

Therefore, we can say that the average velocity in channel I is inhibited more; the loss of the value is 0.3 compared to productivity changes. No exceptional velocity changes were observed channel II: the velocities change in the range of $12 \mathrm{~m} / \mathrm{s}-12.6 \mathrm{~m} / \mathrm{s}$, and the maximum velocity of $12.6 \mathrm{~m} / \mathrm{s}$ is reached in the middle of the channel at measuring points 3 and 4 .

The change of velocities in point 3 is almost symmetrical with respect to the middle of the channel, i.e. the maximum velocity recorded in measuring point 3 in the middle of the channel is $13.2 \mathrm{~m} / \mathrm{s}$. 
The velocities are the lowest at the beginning of the channel; the velocity at the entrance was $11.6 \mathrm{~m} / \mathrm{s}$. The velocities in the second half of the channel reach approximately $12.8 \mathrm{~m} / \mathrm{s}$, and the total average velocity in the channel is quite high $(12.6 \mathrm{~m} / \mathrm{s})$. The drop of velocity to $11.6 \mathrm{~m} / \mathrm{s}$ at measuring point 3 can be related to comparatively large peripheral flow to the previous channel III affecting the dynamic pressure of the flow. The average velocity in channel IV is the lowest in the entire cyclone with the flow amount of $180 \mathrm{~m}^{3} / \mathrm{h}$. The velocity values in the channels $\mathrm{V}$ and VI are very similar and range from 12.2 to $12.7 \mathrm{~m} / \mathrm{s}$. The maximum velocity of $12.7 \mathrm{~m} / \mathrm{s}$ is observed in the middle of channel V. It is important to mention the velocity at measuring point 5 at the end of channel VI, which is the highest in channel VI and is equal to $12.9 \mathrm{~m} / \mathrm{s}$. Furthermore, the average velocity in channel VI is the highest $(12.5 \mathrm{~m} / \mathrm{s})$.

For the analysis of aerodynamic parameters of the flow the maximum flow amount created by the fan is $230 \mathrm{~m}^{3} / \mathrm{h}$. It is more than 3.8 times higher than in the first $\left(60 \mathrm{~m}^{3} / \mathrm{h}\right)$ and almost 1.3 times higher than in the second case $\left(180 \mathrm{~m}^{3} / \mathrm{h}\right)$. The spiral cyclone separator with six channels has been further investigated in order to compare all three cases with different flow amount.

The inflow velocity into cyclone separator was equal to $15.4 \mathrm{~m} / \mathrm{s}$, so it is 1.26 times greater than in the average system, and 3.76 times greater than in minimum analysed productivity. This velocity, on the contrary, especially from $180 \mathrm{~m}^{3} / \mathrm{h}$ air flow amount system velocity distribution does not remain constant throughout the channel, but has a fairly expressed upward trend. The velocity increases by $0.3 \mathrm{~m} / \mathrm{s}$, i.e. almost by $2 \%$ in the middle of channel I at measuring point 3. A significant increase of velocity values is observed in the subsequent points of channel I.

The maximum velocity of $16.2 \mathrm{~m} / \mathrm{s}$ in channel I was reached at point 4 and it was $1.9 \%$ higher than the average velocity in this channel. The velocity decreases slightly at the inflow to channel II, but reaches $16.9 \mathrm{~m} / \mathrm{s}$ at point 2 . This the maximum value measured in channel II at point 5. It is important to mention that flow velocity drops to $15.6 \mathrm{~m} / \mathrm{s}$ at measuring point 3, i.e. it is $8.3 \%$ less than the value in point 2 . However, the average velocity of channel II is 3.5\% higher than in channel I and is equal to $16.44 \mathrm{~m} / \mathrm{s}$. The trend of velocity changes in channel III remains similar to velocities in channel II, but the maximum velocity of $16.9 \mathrm{~m} / \mathrm{s}$ is reached at point 3 and at point 4 the velocity drops by $1.1 \mathrm{~m} / \mathrm{s}$ or $6.9 \%$.

The average velocity in channel III is very similar to the average velocity in channel II and is equal to $16.32 \mathrm{~m} / \mathrm{s}$. The flow rate at all measurement points of channel IV of the spiral cyclone is almost invariable, the average velocity being $16.54 \mathrm{~m} / \mathrm{s}$, and the only value that stands out from other values is measured at point 4 and is equal to $16.7 \mathrm{~m} / \mathrm{s}$. The velocity of $16.5 \mathrm{~m} / \mathrm{s}$ in channel $\mathrm{V}$ remains constant only in the first section of the channel up to point 3 . The velocity slightly increases in the second part of the channel, and the maximum channel velocity of $17 \mathrm{~m} / \mathrm{s}$ is observed in point 5 . This value is also the highest velocity value among all analysed channels at the maximum air flow amount of $230 \mathrm{~m}^{3} / \mathrm{h}$. In this way, the average velocity of channel $\mathrm{V}$ is $16.68 \mathrm{~m} / \mathrm{s}$, which is slightly (only $0.85 \%$ ) higher compared to channel IV. The velocity at the inflow to the last channel VI of the spiral cyclone does not decrease compared to the velocity at measuring point 5 of channel $\mathrm{V}$ and is $17 \mathrm{~m} / \mathrm{s}$.

The axial flow velocity starts decreasing slightly towards the cyclone separator. In this way, the minimum velocity measured at points 3 and 4 of channel VI is $16.7 \mathrm{~m} / \mathrm{s}$. The velocity increases at point 5 and reaches approximately the average channel velocity value, which is equal to $16.82 \mathrm{~m} / \mathrm{s}$. The trend of velocity distribution in cyclone separator channels remains similar in cases, when the inflow velocity is $4.1 \mathrm{~m} / \mathrm{s}$ and $12.2 \mathrm{~m} / \mathrm{s}$.

The authors made comparisons between the numerical and experimental gas tangential velocity profiles, when the axial position is respectively $\mathrm{z}=0.05 \mathrm{~m}$ and $0.07 \mathrm{~m}$ from the top of the cyclone separator (Bernardo et al. 2006). These results were obtained using the RNG turbulence model and the research has shown the compliance with the data of other researchers, so it is assumed that tangential air flow velocity profiles obtained by numerical modelling method correspond to the experimental air flow rates.

\section{Conclusions}

1. The biggest difference of $40 \%$ between the modelling and experimental tests in the analysis of the velocity of channel I of the cyclone was observed in point 5 at the flow rates of $5.2 \mathrm{~m} / \mathrm{s}$ and $3.1 \mathrm{~m} / \mathrm{s}$ at the height of $0.05 \mathrm{~m}$ above the top of the cyclone separator.

2. The comparison of the modelling and experimental results of testing the tangential velocity in 6-channel cyclone showed a slight difference. The maximum error values are observed in channel IV velocities, when the inlet velocity is $15.4 \mathrm{~m} / \mathrm{s}$.

3. The absolute averaged error of experimental and modelling test results obtained by using the RNG k- $\varepsilon$ turbulence model was $5 \%, 5 \%$ and $8 \%$ at the inflow velocity of $4.1 \mathrm{~m} / \mathrm{s}, 12.2 \mathrm{~m} / \mathrm{s}$ and $15.4 \mathrm{~m} / \mathrm{s}$.

4. This article about the air flow velocity distributions is the initial stage of research into multichannel spiral cyclone separators. The main aim of cyclone research is to determine the efficiency of cleaning polluted air in multichannel cyclone separators. 


\section{Acknowledgements}

The research has been conducted in the framework of the project "Application of spiral treatment device with a curvilinear channels for discrete phase treating" (Project No. MIP-095/2012) as a part of Projects conducted by Development Research Teams. The project is co-funded by the Research Council or Lithuania.

\section{References}

Altmeyer, S.; Mathieu, V.; Jullemier, S.; Contal, P.; Midoux, N.; Rode, S.; Leclers, J. P. 2004. Comparison of different models of cyclone prediction performance for various operating conditions using a general software, Chemical Engineering and Processing: Process Intensification 43: 511-522. http://dx.doi.org/10.1016/S0255-2701(03)00079-5

Avci, A.; Karagoz, I. 2003. Effects of flow and geometrical parameters on the collection efficiency in cyclone separators, Journal of Aerosol Science 34: 937-955. http://dx.doi.org/10.1016/S0021-8502(03)00054-5

Baltrènas, P.; Morkūnienė, J.; Vaitiekūnas, P. 2008a. Numerical simulation of solid particle dispersion in the air of Vilnius City, Journal of Environmental Engineering and Landscape Management 16(1): 15-22.

http://dx.doi.org/10.3846/1648-6897.2008.16.15-22

Baltrènas, P.; Vaitiekūnas, P.; Jakstoniene, I.; Konoverskyte, S. 2012. Study of gas-solid flow in a multichannel cyclone, Journal of Environmental Engineering and Landscape Management 20(2): 129-137. http://dx.doi.org/10.3846/16486897.2011.645825

Baltrènas, P.; Vaitiekūnas, P.; Vasarevičius, S.; Jordaneh, S. 2008b. Dispersion modelling of solid particles from vehicle exhaust into the atmosphere, Ekologija 54(2): 117-123. http://dx.doi.org/10.2478/V10055-008-0019-8

Baltrenas, P.; Zagorskis, A. 2010. Investigation into the air treatment efficiency of biofilters of different structures, Journal of Environmental Engineering and Landscape Management 18(1): 23-31. http://dx.doi.org/10.3846/jeelm.2010.03

Bernardo, S.; Mori, M.; Peres, A. P.; Dionísio, R. P. 2006. 3-D computational fluid dynamics for gas and gas-particle flows in a cyclone with different inlet section angles, Powder Technology 162: 190-200. http://dx.doi.org/10.1016/j.powtec.2005.11.007

Gimbun, J.; Chuah, T. G.; Fakhru'l-Razi, A.; Choong, T. S. Y. 2005. The influence of temperature and inlet velocity on cyclone pressure drop: a CFD study, Chemical Engineering and Processing: Process Intensification 44: 7-12. http://dx.doi.org/10.1016/j.cep.2004.03.005

Gong, A. L.; Wang, L. Z. 2004. Numerical study of gas phase flow in cyclones with the repds, Aerosol Science and Technology 38: 506-512. http://dx.doi.org/10.1080/02786820490449548

Gujun, W.; Guogang, S.; Xiaohu, X.; Mingxian, S. 2008. Solids concentration simulation of different size particles in a cyclone separator, Powder Technology (183): 94-104.

Hoffmann, A. C.; Stein, L. E. 2002. Gas cyclone and swirl tubesprinciples, Design and Operation. Berlin: Springer-Verlag. http://dx.doi.org/10.1007/978-3-662-07377-3
Hu, L. Y.; Zhou, L. X.; Zhang, J.; Shi, M. X. 2005. Studies on strongly swirling flows in the full space of volute cyclone separator, AIChE Journal 51(3): 740-749. http://dx.doi.org/10.1002/aic.10354

Jakštonienè, I. 2012. Researches and development of cylindrical multichannel cyclone with adjustable half-rings: Doctoral dissertation. Vilnius: Technika. 140 p.

Jakštonienè, I.; Serebryanskyy, D.; Vaitiekūnas, P. 2011. Experimental research on the work of centrifugal filter when eliminating solid particles from clinker cooling system, in The 8th International Conference "Environmental Engineering": selected papers, May 19-20, 2011, Vilnius, Lithuania, Vol. 1, 134-138. ISBN 978-9955-28-263-1.

Kaya, F.; Karagoz, I. 2008. Performance analysis of numerical schemes in highly swirling turbulent flows in cyclones, Current Science 94(10): 1273-1278.

Luca, F. A.; Ioan, C. A. M. 2012. Air quality management in Iasi city, Environmental Engineering and Management Journal 11(2): 377-383.

Patterson, P. A.; Munz, R. J. 1996. Gas and particle flow patterns at room and elevated temperatures, Canadian Journal of Chemical Engineering 74: 213-221. http://dx.doi.org/10.1002/cjce.5450740206

Raoufi, A.; Shams, M.; Kanani, H. 2008. CFD analysis of flow field in square cyclones, Powder Technology 1-9.

Saltzman, B. E.; Hochstrasser, J. M. 1983. Design and performance of miniature cyclones for respirable aerosol sampling, Environmental Science and Technology 17: 418-424. http://dx.doi.org/10.1021/es00113a011

Sandu, I.-O.; Bulgariu, L.; Macoveanu, M. 2012. Evaluation of environmental impact using active biomonitoring studies of air pollution, Environmental Engineering and Management Journal 11(8): 1527-1534.

Shaw, C. T. 1992. Using computational fluid dynamics. Prentice Hall.

Spalding, D. B. 2002. PHOENICS 3.5 VR CFD CODES [online], [cited 06 October 2013]. Available from Internet: http://www. cham.co.uk

Vaitiekūnas, P.; Banaitytè, R. 2007. Modeling of motor transport exhaust dispersion, Journal of Environmental Engineering and Landscape Management 15(1): 39-46. http://dx.doi.org/10.1080/16486897.2007.9636906

Vaitiekūnas, P.; Jakštonienė, I. 2010. Analysis of numerical modeling of turbulence in a conical reverse-flow cyclone, Journal of Environmental Engineering and Landscape Management 18(4): 321-328. http://dx.doi.org/10.3846/jeelm.2010.37

Vasile, A.; Caldararu, M.; Hornoiu, C.; Bratan, V.; Ionescul, N. I.; Yuzhakova, T.; Redey, A. 2012. Elimination of gas pollutants using $\mathrm{SnO} 2-\mathrm{CeO} 2$ catalysts, Environmental Engineering and Management Journal 11(2): 481-486.

Yakhot, V.; Orszag, S. A.; Thangam, S.; Gatski, T. B.; Speziale, C. G. 1992. Development of turbulence models for shear flows by a double expansion technique, Physics of Fluids 4(7): 1510-1520. http://dx.doi.org/10.1063/1.858424

Zhao, B.; Su, Y.; Zhang, J. 2006. Simulation of gas flow pattern and separation efficiency in cyclone with conventional single and spiral double inlet configuration, Chemical Engineering Research and Design 84: 1158-1165. http://dx.doi.org/10.1205/cherd06040 
Petras VAITIEKŪNAS. Prof. Dr Habil. of Technical Sciences at the Department of Environmental Protection, Vilnius Gediminas Technical University. A diploma in mathematics received from Vilnius University (1965). Dr of Technical Sciences (1973). Dr Habil (1999). Assoc. Prof. (1997). Prof. at the Department of Environmental Protection, VGTU (2002). Training in London, PHOENICS 1.4 EP CFD (January-February 1996) and PHOENICS 3.1 VR CFD (April-May 1998). He is the author and co-author of 3 monographs and more than 200 scientific articles. Research interests: simulated dynamics of fluids, theoretical thermal physics, laminar, transfer processes and simulation of turbulent pollutants.

Egidijus PETRAITIS. Associate Professor of Environmental Engineering Department, VGTU, since 2010. Expertise in projects on air pollution research topics, energy facilities environmental impact assessment, noise dispersion modelling, preparation of feasibility studies, lectures and practical works. A diploma in in the field of technological science (2003), Senior Researcher (2004). Assoc. Prof., Senior Researcher (2009). Prof. at the Department of Environmental Protection, VGTU (2002). Experimental and theoretical studies of environmental systems and environmental technologies, environmental pollution impact on motor testing and evaluation. Author of more than 54 scientific publications; 1 monograph, 2 training books, 1 patent. Author participated in 15 conferences.

Albertas VENSLOVAS. PhD student (2008), Department of Environmental Protection, Vilnius Gediminas Technical University. Master of Science (Environmental Engineering), VGTU, 2008. Bachelor of Science (Environmental Engineering), LŽÜU, 2006. Research interests: environmental protection, environmental noise, environmental noise modelling, scrap-tire crumb rubber application in noise-suppression structures. Author of 5 scientific publications. Author participated in 6 conferences.

Aleksandras CHLEBNIKOVAS. Assistant of the Department of Environmental Protection and engineer of the Research Institute of Environmental Protection at Vilnius Gediminas Technical University (Lithuania). A diploma in Master's of Environmental Protection in the field of technological science received in 2012. Laureate of Students' Scientific Works award established by the Research Academy of Lithuania. Junior researcher of the Agency for Science, Innovation and Technology Design of New Generation Multi-Cyclone (DAKACIKAS). Engineer in the application of the spiral treatment device with a curvilinear channels for discrete phase treating. Author of 2 scientific publications. Participated in 3 conferences. 